УДК 338.242.2

\title{
РАЗВИТИЕ ОРГАНИЗАЦИОННО-ЭКОНОМИЧЕСКОГО МЕХАНИЗМА, ФОРМИРОВАНИЕ МОДЕЛЕЙ, АЛГОРИТМОВ И ПАРАМЕТРОВ НОВОЙ ПАРАДИГМЫ УПРАВЛЕНИЯ В ГОСТИНИЧНОЙ ИНДУСТРИИ Г. МОСКВЫ: ИСТОРИЧЕСКИЙ АСПЕКТ
}

\author{
Чернышев Андрей Валентинович \\ д-р экон. наук, член редколлегии научно-аналитического журнала \\ «Вестник Гуманитарного института»
}

Аннотация: в данной статье раскрыты некоторые методы и формы управления туристско-гостиничным комплексом города, сформулированы и обоснованы предложения и рекомендации, выдвигавшиеся в ходе различных совещаний в органах исполнительной власти, по целесообразности и необходимости структурной перестройки системы управления важной отраслью национальной экономики. Анализируется ряд практических мер, предлагавшихся учёными, по совершенствованию управления Государственного акционерного общества «Москва» (ГАО “Москва"), являвшегося уполномоченной организацией по координации деятельности, представлению интересов Правительства Москвы в индустрии гостеприимства города.

Ключевые слова: индустрия гостеприимства, парадигма управления, гостиница, преобразования, контроль.

\section{DEVELOPMENT OF THE ORGANIZATIONAL AND ECONOMIC MECHANISM, FORMATION OF MODELS, ALGORITHMS AND PARAMETERS OF A NEW MANAGEMENT PARADIGM IN IN THE HOTEL INDUSTRY IN MOSCOW: HISTORICAL ASPECT}

Chernyshev Andrey Valentinovich

\begin{abstract}
: this article reveals some methods and forms of management of the tourist and hotel complex of the city, formulated and justified proposals and recommendations put forward during various meetings in the Executive authorities on the feasibility and necessity of structural adjustment of the management system of an important branch of the national economy. The article analyzes a number of
\end{abstract}


practical measures proposed by scientists to improve the Management of the state joint stock company "Moscow" (GAO "Moscow"), which was an authorized organization for coordinating activities and representing the interests of the Moscow Government in the city's hospitality industry.

Key words: hospitality industry, management paradigm, hotel, transformation, control.

В 2019 г. Москва была награждена известной премией World Travel Awards в главной номинации - «Лучшее туристское направление. Город». В этом контексте, на фоне объективных процессов, проходящих в мировом гостиничном хозяйстве, связанных с имеющимися проблемами в экономике, особенно проявившихся в современный период, учитывая кризисные явления, вызванные пандемией, интересен в плане исторического аспекта, имеющийся позитивный и принципиально новый управленческий опыт в московской индустрии гостеприимства в конце XX века. По данным Мосгорстата, в 1995 г. услугами московских гостиниц воспользовались 991577 иностранных посетителей из 183 стран мира, которыми было реализовано 5439358 ночевок. Иностранцы размещались в 123-х гостиницах вместимостью 33711 номеров на 64938 мест [1, с. 72]. В индустрии гостеприимства столицы РФ трудились десятки тысяч людей. 20 октября 1994 г. распоряжением Мэра Москвы N 525РМ было учреждено Государственное акционерное общество «Москва», которое должно было координировать и осуществлять выполнение задач Правительства Москвы по вопросам развития индустрии гостеприимства города. Основными целями деятельности ГАО «Москва» были: реализация политики Правительства Москвы по вопросам развития гостиничнотуристского комплекса (ГТК) г. Москвы; представление интересов Правительства Москвы в ГТК г. Москвы; развитие гостиничного хозяйства.

По признакам форм собственности и организационно-правовых форм гостиничные предприятия в 1998г. делились на группы, в составе которых: муниципальные предприятия - 20 на 16605 мест (9418 номеров); акционерные общества - 32 на 22242 места (12473 номера); совместные предприятия - 11 на 5160 мест (3182 номера); ведомственные гостиницы - 117 на 34430 мест (16962 номера) [2, с. 39].

По данным ГАО «Москва», общий объем доходов по гостиницам города за 1998г. составил около 3,5 млрд руб., что на 1,3 млрд руб. больше, чем в 1997г. Общий объем доходов по гостиницам с иностранным участием составил 1,4 млрд руб., по гостиницам-акционерным обществам - 0,8 млрд руб., 
муниципальным гостиницам - 0,8 млрд руб. Поступления в бюджет в виде налогов, отчислений и других платежей составили более 1 млрд руб. Только арендной платы от гостиниц «Метрополь», «Рэдиссон-Славянская», «ПентаРенессанс» за 1997-1999гг. поступило около 40 млн долларов США [3, с. 105].

Руководство города уделяло самое пристальное внимание развитию индустрии гостеприимства, регулярно рассматривало данные вопросы на заседаниях Правительства Москвы, принимались нормативные акты. За период с ноября 1994г. по июнь 1998г. органами исполнительной власти Москвы принято более 90 нормативных документов по проблемам развития гостинично-туристского комплекса. Вот только небольшой перечень документов, которые готовились сотрудниками ГАО «Москва» вместе с чиновниками, на основе которых строилась сложная и многоплановая работа по управлению государственной собственностью и определению политики в области развития туризма и гостиничного хозяйства: распоряжение Мэра Москвы №525-РМ от 20 октября 1994г. «Об учреждении государственного акционерного общества «Москва»; распоряжение Мэра Москвы №673-РМ от 22 декабря 1995 г. “О долях (паях пакетах акций) предприятий гостиничнотуристского комплекса, находящихся в государственной собственности г. Москвы”; постановление Правительства Москвы N61 от 25 января 1996г. «Об оплате проживания беженцев в гостиницах»; распоряжение зам. Премьера Правительства Москвы N574-РЗП от 8 мая 1996 г. «О проведении конкурса на аккредитацию в качестве Генерального агента по привлечению инвестиций в гостинично-туристский комплекс г. Москвы»; постановление Правительства Москвы №449 от 28 мая 1996 г. «О программе развития гостиничнотуристского комплекса Москвы»; распоряжение Мэра Москвы N324-РМ от 25 сентября 1996 г. «Об использовании помещений под офисы в гостиницах»; распоряжение Мэра Москвы №585/1-РМ от 10 декабря 1996г. «О создании Московской дисконтной системы»; распоряжение Мэра Москвы №11-РМ от 6 января 1997 г. «О подготовке и переподготовке кадров и повышении квалификации специалистов гостинично-туристского комплекса г.Москвы»; распоряжение Мэра Москвы №53-РМ от 22 января 1997 г. «О создании в Москве сети малых гостиниц»; распоряжение Мэра Москвы №123-РМ от 13 февраля 1997г. «О формировании московских гостиничных цепей»; распоряжение Мэра Москвы N560-PМ от 10 июля 1997 г. «О правилах предоставления и порядке контроля за качеством гостиничных услуг в г. Москве»; распоряжение Мэра Москвы №710-РМ от 13 июля 1998 г. «Об укреплении материальной базы системы подготовки кадров для гостинично- 
туристского комплекса г. Москвы»; распоряжение Мэра Москвы №292-РМ от 5 апреля 1999г. «Об усилении роли профессиональной переподготовки и повышения квалификации специалистов гостинично-туристского комплекса г.Москвы»; распоряжение зам. Премьера Правительства Москвы №675-РЗП от 3 сентября 1999 г. «Об организации профессиональной переподготовки и повышения квалификации специалистов гостиниц г.Москвы».

По инициативе ГАО «Москва» принимались документы, в которых регулировались многочисленные вопросы взаимодействия различных организаций и компаний, работающих на рынке оказания гостиничных услуг в городе. Например, 9 октября 1997г. в целях координации деятельности в области страхования предприятий и организаций ГТК г. Москвы на основе единых условий страхования и льготной тарифной системы, соблюдения принципов добросовестной конкуренции было подписано Соглашение «О совершенствовании организационного взаимодействия в области страхования предприятий гостинично-туристского комплекса (ГТК) г. Москвы уполномоченными страховыми компаниями Правительства Москвы по обслуживанию предприятий ГТК г. Москвы» между ГАО «Москва» и: Открытое Страховое Акционерное Общество "ЖИВА", ОАО "Акционерное Страховое Общество "Лидер", ОАО "Российское страховое народное общество", ЗАО "Страховая группа "Спасские ворота", ЗАО "Страховая компания "Оранта", Открытое Страховое Акционерное Общество "Ингосстрах", ОАО "Страховая акционерная компания "ЭНЕРГОГАРАНТ", ЗАО Страховая Компания "Интеррос-Согласие", ОАО Страховая Компания "ЛУКойл", ОАО САО "РОССИЯ", ЗАО "Военно-страховая Компания", Страховое акционерное общество "Лексгарант", АО "Восточно-Европейское Страховое Агентство", Некоммерческое партнерство "Агентство ГОСТУР". 25 ноября 1997 г. между данными сторонами был подписан Договор «Об организации страхования гостинично-туристского комплекса г. Москвы», который способствовал упорядочиванию страхования в индустрии гостеприимства в условиях развития рыночной экономики, разрешал различные конфликтные ситуации, возникавшие из-за недостаточного количества имевшихся нормативных документов в данной сфере

Следует учитывать, что ежегодно проходили собрания хозяйственного актива работников ГТК г. Москвы и расширенного заседания Координационного совета по туризму при Правительстве Москвы, на которых рассматривались вопросы повседневной и многоплановой деятельности предприятий индустрии гостеприимства города, подводились итоги 
выполнения принятых нормативных документов, определялись цели и задачи на новый период.

Как полагает автор статьи, работавший в 1997 - 2001гг. первым вицепрезидентом ГАО "Москва", в начале XXI века назрела объективная необходимость проведения принципиально новых изменений в системе управления гостиничным хозяйством Москвы, возникли благоприятные структурные условия для конструктивной и эффективной работы по преобразованию ГАО «Москва». На наш взгляд, реализация намеченных руководством города масштабных планов развития индустрии гостеприимства должна была быть связана с: необходимостью оперативного проведения определенных количественных и качественных изменений во всех отраслях городского хозяйства; появлением организационных структур управления, максимально приспособленных к работе в новых экономических условиях; адаптацией уже существующих и хорошо отлаженных механизмов взаимодействия городских служб на горизонтальном уровне к реалиям сегодняшнего дня. О необходимости изменения в системе управления гостиничным хозяйством города говорилось в интервью зам. Мэра Москвы И.Н. Орджоникидзе, опубликованном в газете «Московский комсомолец» в рубрике «Экономический вторник» от 3 апреля 2007г.

Учитывая назревшую необходимость проведения структурной перестройки в действовавшей базисной модели управления гостиничным хозяйством города, предлагалось рассмотреть наиболее рациональный вариант, полноценно работающий в современных рыночных условиях. Специфика гостиничного бизнеса - необходимость постоянной модернизации и расширения материальной базы, периодически возникающая потребность в привлечении значительных средств для реконструкции помещений и замены оборудования, что требовало в условиях уменьшения бюджетного финансирования использования новых нетрадиционных финансовых схем, позволявших аккумулировать денежные ресурсы в количествах, достаточных для решения не только текущих, но и перспективных задач развития индустрии гостеприимства города. Новая парадигма управления гостиничным хозяйством, как нам представляется, позволяла сконцентрировать и централизовать временно свободные собственные денежные средства и направить их на развитие, финансирование реконструкции действующих и строительство новых объектов. Дальнейшее повышение доходности предприятий городской индустрии гостеприимства на современном этапе было невозможно без обеспечения финансового, гостиничного и иного менеджмента, отвечающего 
как современным международным стандартам, так и конкретным особенностям России и Москвы, включая вопросы государственного регулирования развития и поддержки данного рынка услуг.

Говоря о принципах создания новой управляющей модели, анализируя различные проекты вариантов, полагаем, что общими оставались следующие концептуальные подходы, изложенные ниже.

1. С учётом имеющихся реалий необходимо проведение динамичных оперативных и стратегических изменений, уточнение прав, обязанностей и ответственности между различными структурами в сфере управления, контроля и экспертизы в городской индустрии гостеприимства.

2. В коренном совершенствовании нуждается нормативно-методическое обеспечение функционирования ГТК г. Москвы, оценка результативности и эффективности управленческого механизма, порядка определения уровней компетенции и взаимодействия на всех этапах принятия и реализации соответствующих документов.

3. Исключение дублирования и параллелизма в компетенциях управления.

4. Проводимые организационные преобразования должны осуществляться не ради их самих, а быть адекватными, оптимальными, выверенными, последовательными и объективно необходимыми, вытекающими из логики, формата, устоявшейся практики и баланса взаимоотношений, исторически сложившихся в системе управления ГТК г.Москвы, т.е. подчинения и соподчинения:

- I уровень: зам. Мэра Москвы - Комитет по внешнеэкономической деятельности - Комитет по туризму - ГАО «Москва»;

- II уровень: вышеперечисленные правительственные структуры, ГАО «Москва», Департамент имущества, Департамент финансов;

- III уровень: вышеперечисленные правительственные структуры, ГАО “Москва", гостиницы в организационно-правовой форме акционерных обществ, вошедшие в уставный капитал ГАО «Москва»;

- IV уровень: вышеперечисленные правительственные структуры, ГАО «Москва», гостиницы - акционерные общества, где есть доля города.

5. Необходимость сохранения существующей централизованной модели управления в индустрии гостеприимства города.

6. С учетом заданных параметров реорганизации системы управления планируемые изменения не должны негативно отразиться на сформировавшейся структуре руководства гостиницами, т.к. выпадение одного 
звена из общей системы может привести к определенной дестабилизации в процессе регулирования процессами, проходящими в гостиничном комплексе города, утрате важных организаторских функций, необходимости значительного увеличения штата исполнительного аппарата правительственных структур, дублированию и, в конечном счете, потере оперативного контроля и реальными возможностями не только влиять, но и даже прогнозировать стратегические и тактические перспективы в развитии индустрии гостеприимства.

7. Неизбежный и объективно необходимый процесс акционирования муниципальных гостиниц, которые войдут в уставный капитал ГАО «Москва», потребует максимально четкого взаимодействия всех участников управленческой пирамиды. Важно творчески использовать накопленный опыт, дополнив его современным содержанием. Основная задача, которая будет поставлена перед сотрудниками ГАО «Москва», - извлечение максимальной прибыли и направление ее на реконструкцию и модернизацию гостиниц. Планируемые преобразования в структуре управления должны носить осознанный, а не эмоциональный характер, быть продуманы с учетом вполне возможных негативных последствий («Хотели, как лучше, а получилось, как всегда»), способствовать позитивному развитию гостиничной индустрии, а не являться управленческим экспериментом, насаждаемым сверху.

8. Преобразования должны соответствовать духу сегодняшнего времени, т.е. установлению жесткой вертикали власти в условиях рыночных отношений. Однако в создаваемой системе управления в большей степени необходимо, чтобы продолжали действовать экономические и правовые методы, базирующиеся на нормативных актах, положениях, распоряжениях, постановлениях Правительства Москвы и Законах, принимаемых городской Думой.

Как полагает автор данной статьи, проведение намеченных управленческих преобразований, безусловно, могло способствовать повышению эффективной экономической отдачи от деятельности гостиничного хозяйства города.

На наш взгляд, ГАО «Москва» в существовавшем состоянии неспособно было значительно повысить эффективность работы гостиничных предприятий, внедрить новые технологии современного управления бизнесом, увеличить размер налоговых и иных платежей в бюджет города, выполнить комплекс мероприятий, направленных на повышение уровня гостиничного сервиса, осуществить продвижение московских гостиниц на международные рынки 
туристских и гостиничных услуг, привлечь инвесторов для проведения реконструкции существующих и строительства новых гостиничных комплексов, самостоятельно, вместе с директорами гостиниц, заниматься этими вопросами. Планировалось предметно обсудить со всеми заинтересованными сторонами подготовленную модель решения задач по организации, проведению и дальнейшему совершенствованию процесса управления городской гостиничной индустрией. Развитие в Москве современной конкурентоспособной индустрии гостеприимства с широким спектром услуг требовало создания гибкой и эффективной системы управления государственной собственностью, входящей в сложный и разобщенный городской гостиничный комплекс.

С учётом новой парадигмы управления предлагалось на базе ГАО «Москва» создать структуру, в уставный капитал которой внести в качестве вклада капиталы создаваемых ОАО многокорпусных гостиниц города. За собственником, в данном случае, Москва (100\% акций ГАО «Москва» принадлежит городу), в соответствии с его статусом остается право: выпуск нормативной документации, посредством которой он оказывает воздействие на объект управления; сохранение, в соответствии с действующим законодательством, права владения собственностью.

Проведенные преобразования позволяли достигнуть следующие цели и решить основные задачи: обеспечение комплексного подхода в проведении единой политики городских органов управления и уполномоченных структур комплекса по экономической политике и имущественно-земельным отношениям Правительства Москвы; представление интересов Правительства Москвы в гостиничной отрасли; осуществление руководства, координации и контроля использования государственной собственности Москвы, находящейся в объектах гостиничного комплекса и уставных капиталах акционерных обществ; практическая реализация масштабных задач, поставленных руководством города перед гостиничным комплексом; создание определенных экономических, организационных и правовых условий для быстрого, качественного и дальнейшего развития высокодоходной индустрии гостеприимства; организация и проведение в интересах города акционирования, приватизации предприятий и объектов гостиничного хозяйства; внедрение современных методов управления; повышение классности московских гостиниц и уровня обслуживания собственности Москвы в гостиничном хозяйстве; повышение эффективности от деятельности гостиничных предприятий; поиск необходимых финансовых средств на 
реконструкцию гостиниц и номерного фонда; совершенствование деятельности системы органов управления ГАО «Москва» и порядка принятия решений по стратегическим и тактическим вопросам; разработка стратегии деятельности всего комплекса гостиниц, входящих в уставный капитал ГАО «Москва»; стратегический анализ различных видов бизнеса, определение приоритетных областей, которые необходимо развивать; анализ и творческая разработка структуры управления гостиниц, входящих в уставный капитал ГАО «Москва»; оптимизация финансовых потоков и распределения доходов, обеспечивающих наиболее рациональную схему налогообложения доходов предприятий, входящих в ГАО «Москва»; повышение ответственности и заинтересованности в результатах своего труда менеджеров, поставленных на управление; проведение единой кадровой и социальной политики; создание и защита имиджа управляющей компании; обеспечение внутренней и внешней защиты управляющей компании; создание системы эффективного контроля за результатами финансово-хозяйственной деятельности.

В основу преобразований в ГАО «Москва» могли быть положены следующие ключевые моменты: четкое, а зачастую и новое определение функций общества, адекватных и соответствующих задачам сегодняшнего и завтрашнего дня; закрепление новых функций ГАО «Москва» в Уставе общества; концентрация деятельности общества на направлениях стратегического развития; оптимизация структуры управления обществом, сделать её более мобильной; сокращение количества сотрудников общества; результативность деятельности общества; преобразование в конечном итоге ГАО «Москва» в российскую управляющую гостиничную компанию.

Создание новой управляющей модели ГАО «Москва» необходимо было рассматривать как сознательный, планируемый, координируемый и организуемый процесс, с помощью которого обеспечивается деятельность организационной структуры и реализация политики, проводимой Правительством Москвы по развитию гостиничного комплекса. Такой процесс включал в себя: постановку целей; разработку и обеспечение выполнения установленных нормативов; определение затрат; измерение изменений от установленных нормативов; проведение корректирующих мероприятий; оценка результатов и окончательное принятие решений. Необходимость создания новой парадигмы управления и координации использования государственной собственности Москвы в индустрии гостеприимства была продиктована наличием различных условий деятельности предприятий гостиничной отрасли, возникших из новой социально-экономической политики, проводимой 
Правительствами РФ и Москвы. В этих целях ГАО «Москва» должно было представлять определенную функциональную управляющую систему, входящую в организационную структуру городской индустрии гостеприимства, которая осуществляет руководство, координацию и контроль использования государственной собственности Москвы, находящейся в уставном капитале общества, а также содержать в своей структуре совокупность людских и материальных ресурсов, готовых к решению современных задач. Комплексное выполнение предусмотренных работ могло обеспечить рациональное использование собственности Москвы в индустрии гостеприимства, повысить эффективность акционирования и приватизации, создать условия для организации современных высокоэффективных структур, увеличить поступление денежных средств в бюджет города и оказать существенное воздействие на дальнейшее развитие.

Актуальность и целесообразность создания новой управляющей структуры были обусловлены формированием деловой и туристской привлекательности города. Появление новой управляющей модели ГАО «Москва» позволяло бы добиться увеличения въездного и внутреннего туризма, положительно сказаться на повышении качества обслуживания в гостиницах, обеспечить создание новых рабочих места и социальную защиту работников этих предприятий, снизить издержки на управление и повысить рентабельность. То, что сегодня нужна интеграция, многие в гостиничном комплексе понимали. Централизация многих направлений хозяйственной деятельности гостиничных предприятий в ГАО «Москва» предоставила бы всем участникам сокращение расходной части. Это касается материальнотехнического обеспечения, рекламно-выставочной деятельности, кадровой политики, в частности создания «банка передвижения кадров», централизованных технических, ремонтных, транспортных и других служб, обмена гостиницами по всем направлениям и многого другого. В то же время необходимо было помочь гостиницам увеличить доходную часть, прежде всего, путем их загрузки и расширением статей дохода. Этому будут способствовать более высокий имидж в составе управляющей компании, подключение к системам бронирования, поиск новых рынков, перераспределение потоков клиентов по Москве, опять же, централизация рекламно-выставочной деятельности и другого. Уже все это приводит к улучшению качества обслуживания само по себе, но, кроме того, увеличивает прибыль гостиниц, что, в свою очередь, позволит использовать больше денежных средств на их дальнейшее развитие. 
Несомненно, деятельность любой компании в современных российских условиях оценивается по достигнутым конечным результатам, выполнению намеченных планов собственного развития, занятию определенной ниши на рынке, взаимоотношениям с конкурентами, наличию потенциала на дальнейшее совершенствование и перспективу, возможностям гибко и оперативно реагировать на постоянно меняющиеся экономические и правовые условия в стране. Именно под таким углом зрения была рассмотрена работа ГАО «Москва», обобщены положительные моменты, критически осмыслены упущенные возможности и управленческие решения, не приведшие к должному результату. Автор исследования, обладая значительным управленческим опытом работы в крупных коммерческих структурах, имел реальную возможность сравнить эффективность и результативность тех или иных мероприятий, проведенных ГАО «Москва», оценить уровень работы и взаимодействие исполнительного аппарата с многочисленным менеджерским персоналом гостиничного хозяйства города в области подготовки, принятия и реализации необходимых решений и на их основе подготовил конструктивные предложения, которые изложены в виде тезисов в данной статье.

\section{Список литературы}

1. Чернышев А.В. Гостиничная индустрия: проблемы теории и практики технологии управления. - М.: ООО «Агентство рекламы «Товарищ». - 2000. $256 \mathrm{c}$.

2. Чернышев А.В. Гостинично-туристский комплекс г. Москвы (теория, практика, документы). - Информационно-справочное издание. - М.: Издательство «Вестник». - 1998. - 128 с.

3. Чернышев А.В. Организационно-управленческие подходы к формированию корпоративной предпринимательской среды в гостиничном комплексе РФ: теоретико-методологический аспект: монография. - М.: ДПК Пресc. $-2013 .-288$ c.

(C) А.В. Чернышев, 2020 